\title{
Mixoploidia em híbridos de capim-elefante x milheto tratados com agentes antimitóticos
}

\author{
Juscélio Clemente de Abreu $^{(1)}$, Lisete Chamma Davide ${ }^{(2)}$, Antônio Vander Pereira ${ }^{(3)}$ e Sandro Barbosa ${ }^{(1)}$
}

\begin{abstract}
(1)Universidade Vale do Rio Verde, Av. Castelo Branco, oo 82, Chácara das Rosas, CEP 37410-000 Três Corações, MG. E-mail: abreu@tricor.com.br, sandrobarbosa@superig.com.br (2)Universidade Federal de Lavras, Dep. de Biologia, Caixa Postal 37, CEP 37200-000 Lavras, MG. E-mail: Icdavide@ufla.br (3)Embrapa Gado de Leite, Rua Eugênio do Nascimento, oㅡ 610, CEP 36038-330 Juiz de Fora, MG. E-mail: avanderp@cnpgl.embrapa.br
\end{abstract}

Resumo - O objetivo deste trabalho foi avaliar métodos de duplicação cromossômica, com uso de agentes antimitóticos e diversos materiais botânicos como explantes dos híbridos entre capim-elefante (Pennisetum purpureum Schum.) e milheto (Pennisetum glaucum (L.) R. Br.). Utilizaram-se soluções de colchicina a $50 \mathrm{mg} \mathrm{L}^{-1} \mathrm{e}$ $100 \mathrm{mg} \mathrm{L}^{-1}$, e de ciclohexamida $25 \mathrm{mg} \mathrm{L}^{-1}$ :8-hidroxiquinoleína $300 \mathrm{mg} \mathrm{L}^{-1}$ (1:1), aplicadas in vitro em segmentos nodais, e in vivo em plântulas e perfilhos, com diferentes períodos de exposição. O efeito dos antimitóticos foi avaliado por meio da taxa de sobrevivência, do número cromossômico e da presença de anomalias no ciclo celular, em meristemas de raízes das plantas sobreviventes. A colchicina apresentou melhor efeito sobre as plântulas, enquanto a ciclohexamida:8-hidroxiquinoleína (1:1) atuou melhor sobre os perfilhos. Observou-se ocorrência de mixoploidia em células que apresentaram de 14 até 42 cromossomos, o que indica que houve duplicação seguida de eliminação cromossômica, confirmada pelas aberrações cromossômicas. Das células analisadas 86,4\%, em média, apresentaram número cromossômico diferente de 21.

Termos para indexação: Pennisetum purpureum, Pennisetum glaucum, análise citogenética, eliminação cromossômica, híbrido interespecífico.

\section{Mixoploidy in napiergrass $x$ pearl millet hybrids treated with antimitotic agents}

\begin{abstract}
The objective of this work was to evaluate methods of chromosome duplication, using antimitotic agents and several botanical materials as explant hybrids between napiergrass (Pennisetum purpureum Shum.) and pearl millet (Pennisetum glaucum (L.) R. Br.). Colchicine (50 $\mathrm{mg} \mathrm{L}^{-1}$ and $100 \mathrm{mg} \mathrm{L}^{-1}$ ) and cycloheximide:8-hydroxyquinoline (1:1) $\left(25 \mathrm{mg} \mathrm{L}^{-1}: 300 \mathrm{mg} \mathrm{L}^{-1}\right)$ solutions have been applied in vivo to shoots and in vitro to seedlings and tillers. The antimitotic effect has been evaluated through survival rate, chromosome number and presence of cell cycle anomalies at the root tips of surviving plants. The best results have been obtained when seedlings have been treated with colchicine and tillers with cycloheximide: 8-hydroxyquinoline. Mixoploidy has been observed in cells having 14 to 42 chromosomes, indicating that duplication, followed by chromosome elimination, has occurred, which has been confirmed by chromosome aberrations. In the average, 86.4\% of the analyzed cells have presented a chromosome number different from 21.
\end{abstract}

Indexs terms: Pennisetum purpureum, Pennisetum glaucum, cytogenetic analysis, chromosome elimination, interespecific hybrid.

\section{Introdução}

A intensificação da produção de leite de vacas alimentadas exclusivamente em pasto constitui um dos principais objetivos da pecuária nacional. Para tanto, tornase necessária a utilização de gramíneas forrageiras com maior potencial de produção de forragem e qualidade nutritiva. Neste sentido, destaca-se o capim-elefante, associado a outras características forrageiras favoráveis, tais como boa qualidade, palatabilidade, vigor e persistência.
Essas características têm estimulado não só o cultivo dessa espécie, como também o seu melhoramento genético, visando-se ao desenvolvimento de cultivares para utilização sob pastejo e para capineiras (Souza Sobrinho et al., 2005).

O capim-elefante (Pennisetum purpureum Schum.) é uma espécie alotetraplóide, com genoma A’A’BB e $2 \mathrm{n}=4 \mathrm{x}=28$ cromossomos, que pode ser cruzada com o milheto (Pennisetum glaucum (L.) R. Br.), espécie diplóide, com genoma AA e $2 \mathrm{n}=2 \mathrm{x}=14$ cromossomos, e que resulta na obtenção de híbridos de amplo interesse 
forrageiro (Techio et al., 2005). O híbrido interespecífico de capim-elefante com milheto, conhecido como "bana grass", é um triplóide estéril, com $2 \mathrm{n}=3 \mathrm{x}=21$ cromossomos e genoma AA'B, que pode ser mantido via propagação vegetativa. Segundo Pereira et al. (2000), a forragem deste híbrido interespecífico apresenta melhor aceitação pelos bovinos que o próprio capimelefante, entretanto, a esterilidade desse híbrido constitui uma dificuldade em programas de melhoramento genético do capim-elefante, porque os produtores preferem forrageiras cultivadas por meio de sementes.

A restauração da fertilidade do híbrido pode ser conseguida pela duplicação do conjunto cromossômico pelo uso de colchicina (Hanna, 1981; Hanna et al., 1984; Hanna \& Dujardin, 1986), que produz um hexaplóide sintético, que apresenta meiose regular, progênie com alta freqüência de pólen, sementes viáveis de maior tamanho e com menor deiscência, quando comparadas às do capim-elefante, e que viabilizam a propagação deste híbrido via semente.

A obtenção de híbridos hexaplóides utilizando-se plântulas, conforme descrito por Hanna et al. (1984), não permite uma avaliação prévia do comportamento agronômico do triplóide e, como conseqüência, pode-se duplicar os cromossomos de híbridos sem valor forrageiro.

Este trabalho teve como objetivo avaliar os métodos de duplicação cromossômica, com uso de diferentes agentes antimitóticos e diversos materiais botânicos como explantes de híbridos entre capim-elefante e milheto.

\section{Material e Métodos}

Foram utilizadas plântulas e perfilhos, cultivados in vivo, e segmentos nodais cultivados in vitro, de híbridos triplóides obtidos do cruzamento de capim-elefante (parental masculino) x milheto (parental feminino), com exceção do híbrido recíproco (F2000-120), resultante do cruzamento do capim-elefante - F92-38-02 (híbrido intraespecífico) x milheto - M64.

Os diferentes tratamentos foram determinados de acordo com a ordem cronológica dos resultados obtidos. No primeiro experimento, verificaram-se os efeitos das soluções de colchicina (COL), nas concentrações de $50 \mathrm{mg} \mathrm{L}^{-1}$ por 24 horas e $100 \mathrm{mg} \mathrm{L}^{-1}$ por 12 horas, e de ciclohexamida (CHX) $25 \mathrm{mg} \mathrm{L}^{-1}$ :8-hidroxiquinoleína (8-HQ) $300 \mathrm{mg} \mathrm{L}^{-1}$ (1:1) por 2 horas e $30 \mathrm{~min}$, e por 4 horas e 30 min, sobre raízes de plântulas de aproximadamente
$10 \mathrm{~cm}$ de altura. Para cada tratamento, foram utilizadas 30 plântulas. Em seguida, as raízes foram lavadas em água corrente por $30 \mathrm{~min}$, e as plântulas foram submetidas à cultura hidropônica (Neves, 2001).

No segundo experimento, verificaram-se os efeitos dos antimitóticos sobre perfilhos desenvolvidos de gemas axilares, por meio de três protocolos.

No protocolo A, estacas com um nó, com perfilho de aproximadamente $10 \mathrm{~cm}$, foram seccionadas longitudinalmente (corte radial) e separadas em dois grupos com 60 estacas. Um dos grupos foi tratado com hidroxiuréia a 2,5 mM, por 14 horas. Em seguida, 15 estacas de cada grupo foram submetidas aos tratamentos: COL, nas concentrações de $50 \mathrm{mg} \mathrm{L}^{-1} \mathrm{e}$ $100 \mathrm{mg} \mathrm{L}^{-1}$, mais DMSO (dimetilsulfóxido) $2 \%$ por 24 horas, e solução de CHX $25 \mathrm{mg} \mathrm{L}^{-1}: 8-\mathrm{HQ} 300 \mathrm{mg} \mathrm{L}^{-1}$ (1:1), mais DMSO $2 \%$ por 2 horas e 30 min e por 4 horas e 30 min.

Após esta etapa, as estacas foram lavadas por $30 \mathrm{~min}$ em água corrente e submetidas ao cultivo hidropônico (Neves, 2001). Foram coletadas radículas dos perfilhos sobreviventes (fase jovem) de cada tratamento para avaliação citogenética. Estas plantas foram mantidas em cultivo hidropônico até o florescimento (fase adulta), quando foi novamente realizada análise citogenética de pontas radiculares.

No protocolo $\mathrm{B}$, submeteram-se os híbridos às soluções de CHX $25 \mathrm{mg} \mathrm{L}^{-1: 8-H Q} 300 \mathrm{mg} \mathrm{L}^{-1}$ (1:1) por períodos de exposição de 2 horas e $30 \mathrm{~min}$, 3 horas, 3 horas e $30 \mathrm{~min}, 4$ horas e 4 horas e $30 \mathrm{~min}$, e foram utilizadas 10 estacas por tratamento. Após esta etapa, as estacas foram lavadas e submetidas ao cultivo hidropônico, de acordo com o primeiro procedimento.

No protocolo C, 15 perfilhos de gemas axilares, do

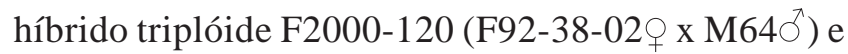
15 de seu recíproco F2000-120 (F92-38-020 x M64ㅇ), foram tratados com CHX $25 \mathrm{mg} \mathrm{L}^{-1} 8$ - $\mathrm{HQ} 300 \mathrm{mg} \mathrm{L}^{-1}$ (1:1), pelo período de 4 horas e $30 \mathrm{~min}$. Em seguida, as estacas foram lavadas e submetidas a cultivo hidropônico, de acordo com os procedimentos anteriores.

No terceiro experimento, plântulas cultivadas in vitro foram expostas a quatro concentrações de COL (50 mg L ${ }^{-1}, 100 \mathrm{mg} \mathrm{L}^{-1}, 200 \mathrm{mg} \mathrm{L}^{-1}$ e $400 \mathrm{mg} \mathrm{L}^{-1}$ ), em meio de cultivo MS sólido suplementado com $3 \mathrm{mg} \mathrm{L}^{-1}$ de BAP e DMSO $2 \%$ e foram autoclavadas a $120^{\circ} \mathrm{C}$ por $20 \mathrm{~min}$. Dezesseis segmentos nodais de aproximadamente $5 \mathrm{~cm}$, cultivados in vitro (MS sólido adicionado de $3 \mathrm{mg} \mathrm{L}^{-1}$ de BAP), foram transferidos para cada um dos meios descritos anteriormente e mantidos 
pelos períodos de 1, 3, 6 e 9 dias. Após cada período, os segmentos nodais foram transplantados para meio de cultivo sem colchicina. As plântulas sobreviventes foram transplantadas para meio de cultivo líquido, composto pelo meio MS mais $0,5 \mathrm{mg} \mathrm{L}^{-1}$ de ácido indolbultírico (AIB) para o enraizamento.

A eficiência dos métodos empregados, para a indução da duplicação cromossômica dos híbridos triplóides, foi averiguada pela contagem do número cromossômico em meristemas de raízes e pelo acompanhamento do ciclo celular, para detecção de anomalias no processo mitótico. Para isso, as raízes das plantas sobreviventes aos tratamentos com os agentes antimitóticos foram separadas em dois grupos. Na obtenção de metáfases, as raízes foram pré-tratadas com solução de CHX $25 \mathrm{mg} \mathrm{L}^{-1}: 8-\mathrm{HQ} 300 \mathrm{mg} \mathrm{L}^{-1}$ (1:1) por 2 horas e $45 \mathrm{~min}$ (Techio et al., 2002). Na análise do ciclo celular não foram realizados pré-tratamentos.

As raízes dos dois grupos foram fixadas em solução de Carnoy (3:1), hidrolisadas em ácido clorídrico (HCl) $1 \mathrm{~N} \mathrm{a} 60^{\circ} \mathrm{C}$, por $8 \mathrm{~min}$, foram, então, coradas com reativo de Schiff, por aproximadamente $15 \mathrm{~min}$, e esmagadas com ácido acético $45 \%$. As lâminas foram secadas ao ar e montadas com Entellan, após a retirada da lamínula com a técnica do nitrogênio líquido (Barbosa et al., 2003).

Em cada experimento, foram analisadas dez raízes e cerca de 290 metáfases por tratamento. O número total de metáfases contadas por tratamento, em cada, experimento, ficou próximo do número determinado pelo dimensionamento de amostras com nível de significância de $95 \%$ e erro amostral de $2 \%$. Para a contagem de aberrações cromossômicas, avaliaram-se todas as células meristemáticas da lâmina, nas dez lâminas confeccionadas por tratamento.

\section{Resultados e Discussão}

A utilização da hidroxiuréia para promover a sincronização das células em divisão (Techio et al., 2002) e, conseqüentemente, a obtenção de maior número de células duplicadas, resultou na morte dos perfilhos tratados com as duas soluções antimitóticas. O uso do DMSO, como carreador da colchicina através das membranas (Rand-Luby et al., 1996; Lima et al., 2001; Jobet et al., 2003), também pode ter contribuído para o baixo nível de sobrevivência dos perfilhos expostos a estes antimitóticos, pois nos experimentos in vivo, onde o DMSO não foi utilizado, houve em média 30\% de sobreviventes, em todos os tratamentos. Ao contrário do que se obteve in vivo, COL + DMSO não afetou o desenvolvimento das plântulas, quando estas foram expostas in vitro.

Comparando-se os efeitos dos dois antimitóticos, verificou-se que apresentaram comportamentos diferenciados em relação à taxa de sobrevivência, nos vários tratamentos utilizados, principalmente, em relação à solução CHX:8-HQ (1:1), que foi prejudicial ao desenvolvimento de plântulas in vivo, em relação à COL + DMSO, que afetou negativamente o desenvolvimento dos perfilhos. Vários autores (Binsfeld et al., 2000; Barbosa, 2004; Koutolis et al., 2005; Poutaraud \& Girardin, 2005) relataram o efeito diferencial de antimitóticos, quando diferentes tecidosalvo e períodos de tratamentos são utilizados.

A exposição de plântulas cultivadas in vitro demonstrou que a colchicina não teve a sua atividade antimitótica alterada, após ter sido autoclavada junto com o meio de cultura à temperatura de $120^{\circ} \mathrm{C}$. Este fato também foi demonstrado por Geoffriau et al. (1997) e corroborado pela análise da curva termogravimétrica (TG) da colchicina (Abreu, 2002).

Os resultados obtidos no experimento de indução de poliploidia, em plântulas in vivo, revelaram que com a diminuição do tempo de exposição e aumento, proporcional, da concentração da colchicina, esta mantém a mesma atividade. Foi verificada uma exceção somente, na classe de 18 cromossomos, que apresentou diferença significativa entre as freqüências observadas (Tabela 1).

Nos diferentes experimentos, as duas substâncias antimitóticas promoveram a alteração do número de cromossomos na grande maioria das células, principalmente nos tratamentos com duração de 4 horas e 30 min, em solução de CHX:8-HQ (1:1) (Protocolos B e C), que geraram em média $86,4 \%$ de células não triplóides. Resultados semelhantes ocorreram com colchicina in vivo, em que 86,5\%, em média, de células também eram não triplóides (Tabela 1). Não foi possível realizar a comparação com os tratamentos de colchicina in vitro, porque eles não geraram raízes suficientes para determinar as freqüências das diferentes classes cromossômicas.

Analisando-se os resultados, infere-se que, mesmo com o uso de materiais botânicos e genéticos diferentes nos experimentos, as substâncias antimitóticas utilizadas causam efeitos semelhantes na duplicação cromossômica e na indução de mixoploidia em híbridos de capim-elefante $\mathrm{x}$ milheto. $\mathrm{O}$ tempo de exposição às 
substâncias antimitóticas também constituiu um fator importante na promoção da duplicação e da mixoploidia nos híbridos, principalmente nos tratamentos com solução de CHX:8-HQ (1:1). Quanto maior o tempo de exposição, maior o número de células com alterações no número de cromossomos (Figura 1).

Na Tabela 2, é possível observar-se o porcentual de aberrações cromossômicas nas plantas sobreviventes, após os tratamentos utilizados nos protocolos A e B; tais plantas evidenciam a eliminação cromossômica e comprovam a mixoploidia, exceção feita às metáfases colchicínicas. Em relação ao protocolo B, verifica-se que o número total de aberrações cromossômicas e as porcentagens de micronúcleos aumentaram, à medida que se aumentou o tempo de exposição dos perfilhos ao antimitótico (Figura 2).

A exposição de perfilhos e de plântulas in vivo aos agentes antimitóticos revelou que existe tendência de as plantas mixoplóides apresentarem maior freqüência de células, com número cromossômico entre 14 e 21. Isto aconteceu tanto nas plantas avaliadas após tratamentos quanto nas avaliadas após o florescimento. Portanto, os tratamentos com os dois antimitóticos apresentaram atividades idênticas, na alteração do número de cromossomos dos híbridos de capim-elefante com milheto. As células hexaplóides formadas eliminam normalmente mais de 21 cromossomos e formam plantas mixoplóides (Tabela 1).

A eliminação cromossômica é um fenômeno comum entre outros híbridos interespecíficos de gramíneas, tais como Hordeum vulgare x H. bulbosum e Avena sativa x A. sterilis (Giacomelli et al., 2000). Muitos exemplos na literatura demonstram que a eliminação cromossômica de um genoma parental pode ser parcial ou total (Adamowski et al., 1998; Peters et al., 1999; Pagliarini \& Suaki, 2003). Em muitos casos, a eliminação cromossômica é dependente do tecido e é influenciada pelas condições fisiológicas das células. Diversos mecanismos de eliminação cromossômica já foram descritos, inclusive a fragmentação de cromossomos, formação de micronúcleos, degradação da cromatina, cromossomos não-orientados na metáfase e retardatários em anáfase (Singh, 2002).

Os híbridos triplóides interespecíficos de capimelefante (tetraplóide) com milheto (diplóide) também são estáveis, têm uma proporção genômica de 2C:1M (C: genomas A'B de capim-elefante e M: genoma A do milheto), porém quando se alterou esta proporção, devido à ação das substâncias antimitóticas, as células induzidas dos híbridos começaram a eliminar os cromossomos.

Houve eliminação tanto de genomas completos, quanto do $\mathrm{B}$, possivelmente, que não foi observado nas células com 28 cromossomos, como também de cromossomos individuais, uma vez que células mixoplóides, principalmente as que continham entre 14 e 21 cromossomos (números diferentes da série euplóide), foram encontrados nas plantas jovens e na adulta.

A eliminação cromossômica ocorreu, provavelmente, em razão tanto de problemas de proporções de genomas, quanto de controle da expressão gênica. A hipótese de divisão assincrônica foi descartada, porque nos híbridos

Tabela 1. Porcentagens do número de cromossomos encontrados nas plantas sobreviventes dos diferentes experimentos, após tratamento com os antimitóticos colchicina (COL) e ciclohexamida:8-hidroxiquinoeína (CHX:8-HQ), na proporção de 1:1.

\begin{tabular}{|c|c|c|c|c|c|c|c|c|c|c|c|c|}
\hline \multirow[t]{2}{*}{ Tratamento/concentração } & \multirow[t]{2}{*}{ Tempo } & \multicolumn{11}{|c|}{ Freqüências de classes de números cromossômicos (\%) } \\
\hline & & 14 & 16 & 18 & 21 & 24 & 28 & 30 & 32 & 34 & 38 & 42 \\
\hline$\overline{\operatorname{COL}}\left(50 \mathrm{mg} \mathrm{L}^{-1}\right)$ & 24 horas & 52,0 & - & 1,7 & 13,0 & 0,7 & 30,0 & 0,3 & - & 1,0 & - & 1,4 \\
\hline $\operatorname{COL}\left(100 \mathrm{mg} \mathrm{L}^{-1}\right)$ & 12 horas & 47,0 & 1,7 & $12,0 *$ & 14,0 & - & 23,0 & - & 1,0 & - & 0,3 & 0,7 \\
\hline Protocolo A & Planta 1 jovem & $11,5^{*}$ & 12,5 & 25,0 & 37,5 & 3,8 & 1,9 & 0,9 & 0,9 & 2,9 & 1,9 & 1,0 \\
\hline CHX:8-HQ (1:1) & Planta 1 adulta & 17,2 & 19,3 & 30,1 & 29,8 & 1,9 & 2,1 & - & - & - & - & - \\
\hline $25 \mathrm{mg} \mathrm{L}^{-1}: 300 \mathrm{mg} \mathrm{L}^{-1}$ & Planta 2 jovem & 5,9 & 10,2 & 34,4 & 43,0 & 1,6 & 1,9 & 0,5 & 1,0 & 0,5 & 1,0 & - \\
\hline+ & Planta 2 adulta & 8,7 & 17,8 & 31,5 & 40,2 & 1,2 & - & - & 1,0 & - & 0,2 & - \\
\hline \multirow[t]{2}{*}{ DMSO } & Planta 3 jovem & 3,6 & 11,7 & 25,5 & 36,5 & 2,2 & $8,7^{*}$ & - & 4,4 & 3,6 & 3,6 & - \\
\hline & Planta 3 adulta & 9,4 & 15,3 & 30,3 & 38,5 & 2,1 & 2,9 & 0,7 & - & - & - & - \\
\hline Protocolo B & 2 horas e $30 \mathrm{~min}$ & 8,3 & 6,9 & 24,6 & 49,1 & 1,0 & 2,0 & 0,3 & 3,5 & 1,3 & 1,0 & 2,0 \\
\hline CHX:8-HQ (1:1) & 3 horas & 11,3 & 8,9 & 23,9 & 45,3 & 2,7 & 2,2 & 0,5 & 1,9 & 0,7 & 1,0 & 1,6 \\
\hline \multirow[t]{3}{*}{$25 \mathrm{mg} \mathrm{L}^{-1}: 300 \mathrm{mg} \mathrm{L}^{-1}$} & 3 horas e $30 \mathrm{~min}$ & 15,7 & 9,7 & 26,7 & 43,9 & 1,0 & 0,4 & - & 1,3 & - & 1,3 & - \\
\hline & 4 horas & 21,5 & 20,2 & 36,9 & 15,4 & - & 1,5 & - & - & 1,5 & 1,5 & 1,5 \\
\hline & 4 horas e $30 \mathrm{~min}$ & 55,3 & 12,0 & 12,7 & 13,5 & 0,7 & 2,1 & - & - & 1,5 & 1,5 & 0,7 \\
\hline Protocolo C & 4 horas e $30 \mathrm{~min}$ & & & & & & & & & & & \\
\hline CHX:8-HQ (1:1) & Genótipo $1^{(1)}$ & 8,0 & 12,2 & 33,4 & 12,3 & 10,0 & $16,4^{*}$ & 2,2 & 2,2 & 2,2 & 1,1 & - \\
\hline $25 \mathrm{mg} \mathrm{L}^{-1}: 300 \mathrm{mg} \mathrm{L}^{-1}$ & Genótipo $2^{(2)}$ & 10,0 & 13,5 & 36,0 & 15,1 & 15,3 & 8,3 & 1,8 & - & - & - & - \\
\hline
\end{tabular}

${ }^{(1) G e n o ́ t i p o ~ 1: ~ F 200-1201 ~=~(F 92-38-02 @ ~ x ~ M 64 ð) . ~(2) G e n o ́ t i p o ~ 2: ~ F 2000-120 ² ~=~(F 92-38-02 ð ~ x ~ M 64 @) . ~ * D i f e r e n c ̧ a ~ s i g n i f i c a t i v a ~ a ~ 5 \% ~ d e ~}$ probabilidade, pelo teste de igualdade de duas proporções. 
triplóides os genomas A, A' e B segregam-se normalmente. Gildenhuys \& Brix (1961, 1964), citados por Barbosa (2004), mostram que o hexaplóide de capimelefante com milheto, induzido pelo tratamento do híbrido triplóide com colchicina, demonstrou instabilidade no número cromossômico somático, de 36 a 49, com $2 n=42$ cromossomos que ocorreram mais freqüentemente. Os autores concluíram que a variação do número cromossômico é, provavelmente, controlada geneticamente, e que esses genes só se expressam quando estão em dose dupla ou elevada. Aparentemente, segundo esses autores, tais genes são hemizigóticos ineficientes.

Raman \& Krishnaswami (1960), citados por Techio et al. (2002), relataram que há grandes chances de obtenção de um híbrido alodiplóide AA' fértil e com caracteres desejáveis de Pennisetum purpureum e P. glaucum, a partir da eliminação do genoma B no

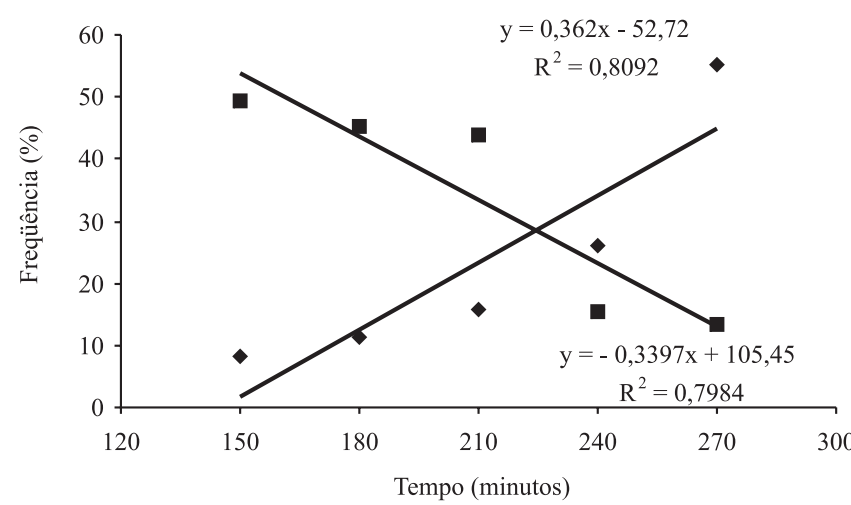

Figura 1. Porcentagens de células com 14 ( $\bullet$ e 21 cromossomos (ם), em diferentes tempos de exposição dos perfilhos à ciclohexamida:8-hidroxiquinoleína (CHX:8-HQ; 1:1). híbrido triplóide, obtido do cruzamento de milheto 2x (AA) com um autoalotetraplóide (AAA'B). Em sucessivos cruzamentos de P. glaucum (2x) com anfidiplóide (6x), Gildenhuys \& Brix (1969), citados por Jauhar (1981), observaram uma eliminação cromossômica seletiva nos zigotos híbridos e sugeriram que os cromossomos do genoma B têm uma maior chance de serem eliminados do que os do genoma A' de $P$. purpureum.

Como relatado anteriormente, a exposição de perfilhos desenvolvidos de gemas axilares (Protocolos B e C) e de plântulas mostrou que existe uma tendência de as células mixoplóides apresentarem 14 cromossomos morfologicamente semelhantes (Figura 3 ), que podem corresponder a núcleos AA, A'A' ou AA'. Estudos deverão ser conduzidos para se tentar confirmar essa hipótese.

Embora ainda existam dúvidas sobre como explicar a eliminação cromossômica, pôde-se verificar, por meio do Protocolo C, que seu controle é nuclear, pois a direção do cruzamento para obtenção do híbrido, aparentemente, não influenciou na eliminação, já que a única diferença significativa encontrada entre os tratamentos ocorreu para as freqüências da classe de 28 cromossomos (Tabela 1).

A eliminação cromossômica não foi descrita por Hanna et al. (1984), que relataram que 30\% dos híbridos triplóides sobreviventes de capim-elefante com milheto eram hexaplóides, após a ação de colchicina $50 \mathrm{mg} \mathrm{L}^{-1}$ por 24 horas. No referido trabalho, os autores relataram apenas o sucesso com a duplicação cromossômica, demonstrada pela presença de pólen nas panículas.

Uma hipótese para se explicar a ocorrência de mixoploidia, neste trabalho, é a utilização de ecótipos com controle genético diferenciado. Além disso, a amostra de clones, utilizada para obtenção dos triplóides,

Tabela 2. Porcentagens de aberrações cromossômicas encontradas nas plantas sobreviventes, após os tratamentos com ciclohexamida:8-hidroxiquinoleína (CHX:8-HQ), na proporção de 1:1.

\begin{tabular}{|c|c|c|c|c|c|c|c|c|c|c|c|}
\hline \multirow[t]{3}{*}{ Aberração $^{(1)}$} & \multicolumn{6}{|c|}{ Protocolo A } & \multirow{2}{*}{\multicolumn{5}{|c|}{ Protocolo B (tempo) }} \\
\hline & \multicolumn{2}{|c|}{ Planta 1} & \multicolumn{2}{|c|}{ Planta 2} & \multicolumn{2}{|c|}{ Planta 3} & & & & & \\
\hline & $\begin{array}{c}\text { Fase } \\
\text { jovem }\end{array}$ & $\begin{array}{c}\text { Fase } \\
\text { adulta }\end{array}$ & $\begin{array}{c}\text { Fase } \\
\text { jovem }\end{array}$ & $\begin{array}{c}\text { Fase } \\
\text { adulta }\end{array}$ & $\begin{array}{c}\text { Fase } \\
\text { jovem }\end{array}$ & $\begin{array}{c}\text { Fase } \\
\text { adulta }\end{array}$ & $\begin{array}{l}2 \text { horas } \\
\text { e } 30 \mathrm{~min}\end{array}$ & 3 horas & $\begin{array}{c}3 \text { horas e } \\
30 \mathrm{~min}\end{array}$ & 4 horas & $\begin{array}{l}4 \text { horas } \\
30 \mathrm{~min}\end{array}$ \\
\hline MTC & 43,1 & 51,8 & 38,5 & 34,0 & 53,3 & 45,1 & 68,6 & 82,3 & 66,9 & 45,6 & 36,9 \\
\hline CNM & 25,3 & 14,3 & 23,0 & 12,2 & 7,7 & 1,8 & 22,0 & 8,1 & 13,4 & 10,1 & 9,8 \\
\hline $\mathrm{MIC}$ & 29,4 & 3,9 & 38,5 & 53,0 & 37,8 & 43,0 & 8,5 & 10,5 & 13,4 & 39,1 & 48,3 \\
\hline $\mathrm{ACP}$ & 1,3 & - & - & - & 1,1 & - & 0,6 & - & 4,7 & 5,1 & 3,3 \\
\hline $\mathrm{ACA}$ & 0,7 & - & - & 0,7 & - & - & - & - & 1,6 & - & 1,6 \\
\hline Total & 153 & 209 & 195 & 147 & 182 & 102 & 118 & 124 & 127 & 138 & 184 \\
\hline
\end{tabular}

(1)MTC: metáfase colchicínica; CNM: cromossomos não-orientados na metáfase; MIC: micronúcleos; ACP: anáfase com ponte; ACA: anáfase com cromossomos atrasados. 


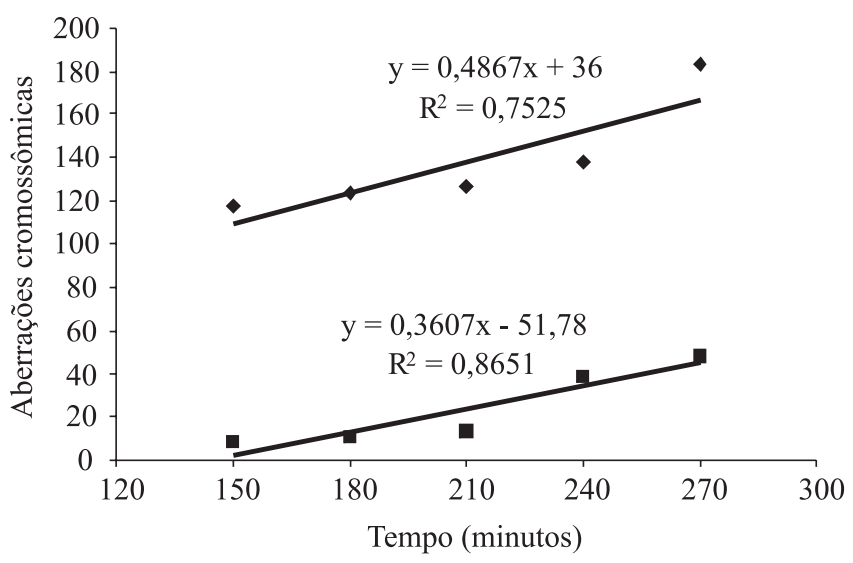

- $\mathrm{N}^{\mathrm{o}}$ total de aberrações $\quad$ - Porcentagens de micronúcleos

Figura 2. Número total de aberrações cromossômicas e porcentagens de micronúcleos encontradas em células de plantas sobreviventes, após os diferentes períodos de exposição à ciclohexamida:8-hidroxiquinoleína (CHX:8-HQ; 1:1). pode não ter sido representativa da variabilidade existente entre os acessos do Banco de Germoplasma da Embrapa Gado de Leite, visto que o critério utilizado para seleção foi a superioridade para caracteres forrageiros. É possível, também, que os clones utilizados apresentassem relações de parentesco e, portanto, compartilhassem o mesmo controle genético para eliminação de cromossomos.

A eliminação de cromossomos em híbridos interespecíficos é uma ferramenta muito valiosa em programas de melhoramento genético (Giacomelli et al., 2000). Com a eliminação parcial de cromossomos, podemse gerar novas variedades de híbridos, enquanto a eliminação total de um genoma do híbrido de capim-elefante e milheto pode permitir a formação de variedades diplóides férteis, que poderão servir de ponte nos cruzamentos com milheto para, futuramente, por meio de retocruzamentos, introduzir características desejáveis no capim-elefante.

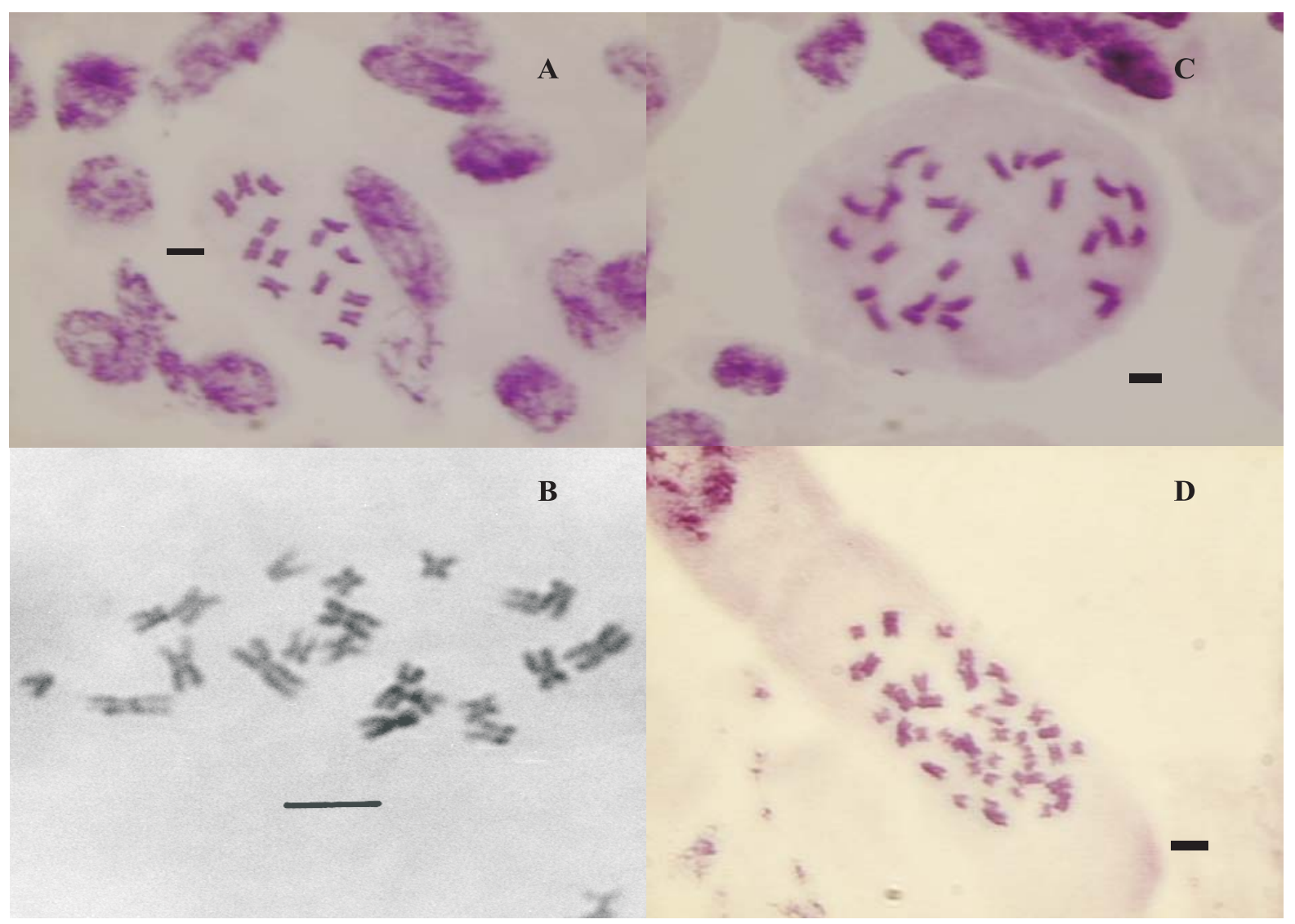

Figura 3. Metáfases mitóticas em híbridos de capim-elefante x milheto, tratados com soluções antimitóticas com 14 cromossomos (A), 28 cromossomos (B), 21 cromossomos (C) e 42 cromossomos (D). Barra: $5 \mu \mathrm{m}$. 


\section{Conclusões}

1. As soluções antimitóticas utilizadas atuam de maneira semelhante sobre os híbridos triplóides e resultam na duplicação cromossômica, seguida de eliminação completa ou parcial de genomas.

2. Os antimitóticos ciclohexamida:8-hidroxiquinoleína (1:1) e colchicina apresentam efeitos semelhantes em diferentes materiais botânicos e genéticos de híbridos de capim-elefante $\mathrm{x}$ milheto.

3. A eliminação cromossômica se expressa quando diferentes proporções genômicas são produzidas nos híbridos de capim-elefante $\mathrm{x}$ milheto.

4. Nos híbridos de capim-elefante x milheto, o controle da eliminação cromossômica é nuclear.

\section{Agradecimentos}

À Fapemig, pelo apoio financeiro; à Embrapa Gado de Leite, pelo fornecimento dos híbridos; à Universidade Federal de Lavras, pelo espaço cedido para realização do experimento; à Universidade Vale do Rio Verde, pelo apoio.

\section{Referências}

ABREU, J.C. de. Mixoploidia em híbridos de capim-elefante $\mathbf{x}$ milheto tratados com agentes antimitóticos. 2002. 72p. Tese (Doutorado) - Universidade Federal de Lavras, Lavras.

ADAMOWSKI, E.D.; PAGLIARINI, M.S.; BATISTA, L.A.R. Chromosome elimination in Paspalum subciliatum (Notata group). Sexual Plant Reproduction, v.11, p.272-276, 1998.

BARBOSA, S. Micropropagação e duplicação cromossômica de híbridos triplódes de capim-elefante e milheto. 2004. 119p. Tese (Doutorado) - Universidade Federal de Lavras, Lavras.

BARBOSA, S.; DAVIDE, L.C.; PEREIRA, A.V. Cytogenetics of Pennisetum prupureum Schumck x Pennisetum glaucum L. hybrids and their parents. Ciência e Agrotecnologia, v.27, p.26-35, 2003.

BINSFELD, P.C.; PETERS, J.A.; SCHNABL, E.H. Efeito de herbicidas sobre a polimerização dos microtúbulos e indução de micronúcleos em protoplastos de Helianthus maximiliani. Revista Brasileira de Fisiologia Vegetal, v.12, p.263-272, 2000.

GEOFFRIAU, E.; KAHANE, R.; BELLAMY, C.; RANCILLAC, M. Ploidy stability and in vitro chromosome doubling in gynogenic clones of onion (Allium cepa L.). Plant Science, v.122, p.201-208, 1997.

GIACOMELLI, F.R.B.; PAGLIARINI, M.S.; ALMEIDA, J.L. de. Elimination of micronuclei from microspores in a Brazilian oat (Avena sativa L.) variety. Genetics and Molecular Biology, v.23, p.681-684, 2000.

HANNA, W.W. Method of reproduction in napiergrass and in the $3 \mathrm{X}$ and $6 \mathrm{X}$ alloploid hybrids with pearl millet. Crop Science, v.21, p.123-126, 1981.
HANNA, W.W.; DUJARDIN, M. Cytogenetic of Pennisetum schweinfurthii Pilger and its hybrids with pearl millet. Crop Science, v.26, p.499-553, 1986.

HANNA, W.W.; GAINES, T.P.; GONZALEZ, B.; MONSON, W.G. Effect of ploidy on yield and quality of pearl millet $x$ napiergrass hybrids. Agronomy Journal, v.76, p.969-971, 1984.

JAUHAR, P.P. Cytogenetics and breeding of pearl millet and related species. New York: A.R. Liss, 1981. 289p.

JOBET, C.; ZUNIGA, J.; CAMPOS de Q.H. Plantas doble haploides generadas por cruza intergenerica de trigo x maiz. Agricultura Técnica, v.63, p.323-328, 2003.

LIMA, A.C.; SANTOS, R.A. dos; ALMEIDA, F.A.G.; BANDEIRA, C.T. Chemical stimulants in the extraction of the gum of cashew tree. Ciência Rural, v.31, p.409-415, 2001.

KOUTOLIS, A.; ROY, A.T.; PRICE, A.; SHERRIFF, L.; LEGGETT, G. DNA ploidy level of colchicines-treated hops (Humulus lupulus L.). Scientia Horticulturae, v.105, p.263-268, 2005.

NEVES, A.L.R.A. Cultivo de milho hidropônico para alimentação animal. Viçosa: CPT, 2001. 46p.

PAGLIARINI, M.S.; SUAKI, R.M. Chromosome transfer and chromosome elimination in Avena sativa. Nucleus, v.46, p.104-107, 2003.

PEREIRA, A.V.; FERREIRA, R.P.; PASSOS, L.P.; FREITAS, V.P.; VERNEQUE, R.; BARRA, R.B.; SILVA, C.H.P.E. Variação da qualidade de folhas em capim-elefante (Pennisetum purpureum) e híbridos de capimelefante x milheto ( $P$. purpureum x P. glaucum), em função da idade da planta. Ciências e Agrotecnologia, v.24, p.490-499, 2000.

PETERS, J.A.; BOBROWSKI, V.L.; ROSINHA, G.M.S. Produção de haplóides e duplo-haplóides. In:TORRES, A.C.; CALDAS, L.S.; BUSO, J.A. Cultura de tecidos e transformação genética de plantas. Brasília: Embrapa-CNPH, 1999. v.2, p.569-611.

POUTARAUD, A.; GIRARDIN, P. Influence of chemical characteristics of soil on mineral and alkaloid seed contents of Colchicum autumnale. Environmental and Experimental Botany, v.54, p.101-108, 2005.

RAND-LUBY, L.; POMMIER, R.F.; WILLIAMS, S.T.; WOLTERING, E.A.; SMALL, K.A.; FLETCHER, W.S. Improved outcome of surgical flaps treated with topical dimethylsulfoxide. Annals of Surgery, v.224, p.583-590, 1996.

SINGH, R.J. Plant Cytogenetics. $2^{\text {nd }}$ ed. Boca Raton: CRC Press, 2002. 463p.

SOUZA SOBRINHO, F. de; PEREIRA, A.V.; LÉDO, F.J. da S.; BOTREL, M. de A.; OLIVEIRA, J.S.; XAVIER, D.F. Avaliação agronômica de híbridos interespecíficos entre capim-elefante e milheto. Pesquisa Agropecuária Brasileira, v.40, p.873-880, 2005.

TECHIO, V.H.; DAVIDE, L.C.; PEREIRA, A.V. Genomic analysis in Pennisetum purpureum x P. glaucum hybrids. Caryologia, v.58, p.2833, 2005.

TECHIO, V.H.; DAVIDE, L.C.; PEREIRA, A.V.; BEARZOTI, E. Cytotaxonomy of some species and of interspecific hybrids of Pennisetum (Poaceae, Poales). Genetics and Molecular Biology, v.25, p.203-209, 2002. 